\title{
Particle Behavior Investigation for Different Structures of Hoppers
}

\author{
Panpan Zhang ${ }^{1,2}$, Qingwen Chen ${ }^{1, *}$ \\ ${ }^{1}$ China Waterborne Transport Research Institute, Beijing,100088, China. \\ ${ }^{2}$ Key Laboratory of Logistics Equipment \& Control Engineering, Beijing 100088, China.
}

\begin{abstract}
In this paper, two different kinds of hoppers were proposed. In order to investigate particle behavior in hoppers, the discrete element method (DEM) was introduced and soybeans were chosen as test material Particle behavior of four different samples were simulated under different flow rate. Results reveal that the deflection cone greatly affected the particle behavior. After adding the deflection cone in the hopper, the trajectory of particle material can be restrained and the dust diffusion can be reduced.different distances of the deflection cone showed different guiding effect on the particle movement.
\end{abstract}

\section{1 introduction}

With the development of new corona-virus, global food trade is extremely active. Shipping is the most important means of international food transportation. When the ship arrives at the port, grain loading and unloading process is also an important area of port environmental protection. The ship is unloaded and grain will enter the silo. if grain is going be distributed, it is necessary to use hoppers for truck loading. The hopper in the distribution station is an important equipment. the performance of the hopper has a great influence on the bulk cargo handling. In this process, it is the prone point of dust shown in Figure 1. In recent years, researchers and some companies focus on the study of particle behavior and dust suppression [1-3].

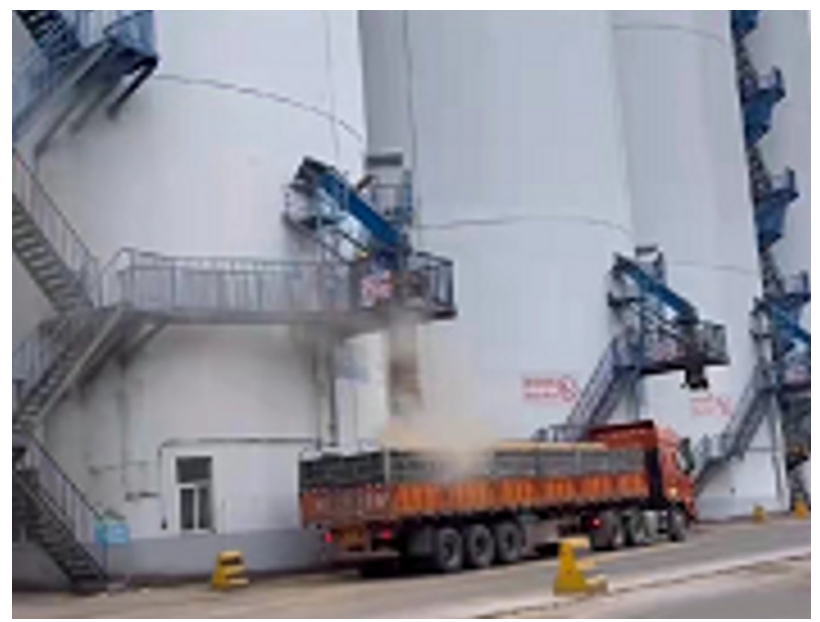

Fig. 1 The dust caused in the truck loading

The discrete element method known as DEM is now widely applied to investigate the particle behavior in areas of food, mineral and chemical industries. The software packages EDEM were developed based on the discrete element method which can model various materials such as large rocks, fine powders, grains, fibers, and tablets and can provide realistic material behavior to facilitate the equipment development as shown in Figure 2 [4-5].

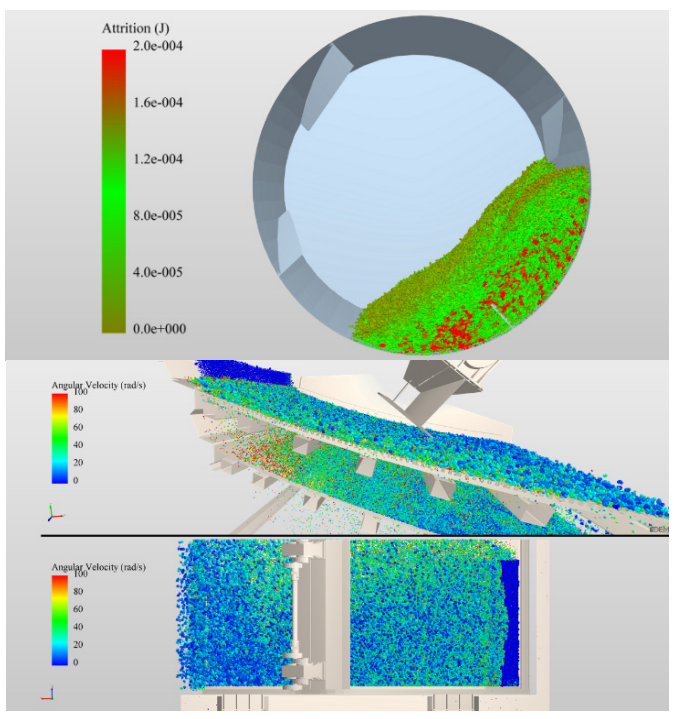

Fig. 2. The application of the software EDEM [6].

In this paper, different structures of hoppers were proposed. the discrete element method was used via the the software package EDEM and investigation was carried out to evaluate the particle behaviors. the influence factors of different deflection cone positions and different material flow rate were simulated.

\section{Hopper Design}

In order to access the particle behavior of different hoppers, two different kinds of hoppers were designed.

\footnotetext{
* Corresponding author: chenqw@wti.ac.cn
} 
the hopper shown in Figure 3 is the same as the one used in ports. Unlike the common hopper, a deflection cone as shown in Figure 4 was set in the hopper to change the flow of materials.

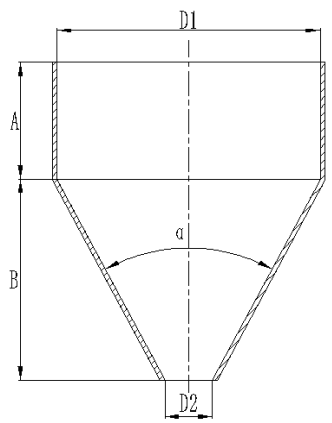

Fig. 3. The structure of the hopper

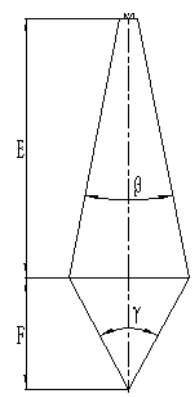

Fig. 4. The structure of the deflection cone

In Figure 3, the diameter of the inlet marked as D1 and the diameter of the outlet marked D2 were set as the fixed value. Paramenters of the hopper were listed in Table 1. The parameterS of the deflection cone were shown in Table 2.

Table 1. Parameters of hoppers

\begin{tabular}{|c|c|c|c|c|}
\hline $\begin{array}{c}\mathrm{D} 1 \\
(\mathrm{~mm})\end{array}$ & $\begin{array}{c}\mathrm{D} 2 \\
(\mathrm{~mm})\end{array}$ & $\begin{array}{c}\mathrm{A} \\
\left({ }^{\circ}\right)\end{array}$ & $\begin{array}{c}\mathrm{A} \\
(\mathrm{mm})\end{array}$ & $\begin{array}{c}\mathrm{B} \\
(\mathrm{mm})\end{array}$ \\
\hline 280 & 50 & 56 & 125 & 215 \\
\hline
\end{tabular}

Table 2. Parameters of a deflection cone

\begin{tabular}{|c|c|c|c|}
\hline $\mathrm{E}(\mathrm{mm})$ & $\mathrm{F}(\mathrm{mm})$ & $\beta\left(^{\circ}\right)$ & $\gamma\left(^{\circ}\right)$ \\
\hline 280 & 120 & 22 & 56 \\
\hline
\end{tabular}

In order to discover the position influence of the deflection cone in Figure 4 , different heights in were set as shown in Table 3.

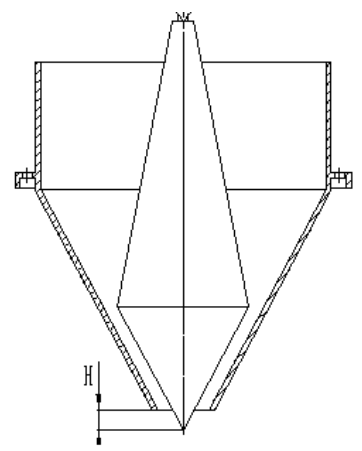

Fig. 4. The structure of the deflection cone

Table 3. Height setting of a deflection cone

\begin{tabular}{|c|c|c|c|}
\hline Sample 1 & Sample 2 & Sample 3 & Sample 4 \\
\hline $\begin{array}{c}\text { No } \\
\text { deflection } \\
\text { cone }\end{array}$ & $\mathrm{H} 1(\mathrm{~mm})$ & $\mathrm{H} 2(\mathrm{~mm})$ & $\mathrm{H} 3(\mathrm{~mm})$ \\
\cline { 2 - 4 } & 0 & 20 & 30 \\
\hline
\end{tabular}

\section{Simulation of different hoppers}

The physical parameters of the soybeans and the hopper were shown in Table 4 and Table 5 . The equivalent particle diameter of soybeans is random distributed from $3.2 \mathrm{~mm}$ to $4 \mathrm{~mm}$ in diameter. During the soybeans unloading simulation process, the mass flow rate of soybeans is $2500 \mathrm{~kg} / \mathrm{h}$.

Table 4. Physical parameters of soybeans and the hopper

\begin{tabular}{|c|c|c|c|}
\hline Item & $\begin{array}{c}\text { Density/kg.m- } \\
3\end{array}$ & $\begin{array}{c}\text { Shear } \\
\text { modulus } / \mathrm{Pa}\end{array}$ & $\begin{array}{c}\text { Poisso } \\
\text { n's } \\
\text { ratio }\end{array}$ \\
\hline Soybean & 1222 & $2.0 \mathrm{e}+07$ & 0.4 \\
\hline Steel & 7900 & $1.0 \mathrm{e}+08$ & 0.25 \\
\hline
\end{tabular}

Table 5. Contact parameters of different materials

\begin{tabular}{|c|c|c|c|}
\hline Item & $\begin{array}{c}\text { Restitution } \\
\text { coefficient }\end{array}$ & $\begin{array}{c}\text { Coefficient } \\
\text { of static } \\
\text { friction }\end{array}$ & $\begin{array}{c}\text { Coefficient } \\
\text { of rolling } \\
\text { friction }\end{array}$ \\
\hline $\begin{array}{c}\text { Soybean- } \\
\text { Soybean }\end{array}$ & 0.668 & 0.2 & 0.02 \\
\hline $\begin{array}{c}\text { Soybean- } \\
\text { Steel }\end{array}$ & 0.72 & 0.2 & 0.0262 \\
\hline
\end{tabular}

Calculation domain of the hopper was set as a cylinder down the outlet of the hopper with $600 \mathrm{~mm}$ in height and $600 \mathrm{~mm}$ in diameter as shown in Figure 5. During the simulation, Hertz-Mindlin non-slip model was adopted. 


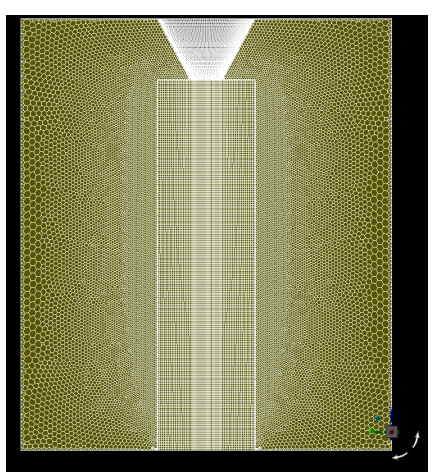

Fig. 5. Calculation domain setting

\section{Results and Discussion}

Particle behaviors of samples shown in Table 3 were simulated as shown in Figure 6 and Figure 7. the simulation results reveal that the deflection cone can guide the flow of soybeans as well as the dust. However the distance between the deflection cone and the outlet of the hopper have a different and significant influence on the material flow. As the distance increases, the gap between the hopper and the deflection cone is decreasing. Decreasing of the gap can compress the soybean flow which will slow down the flow in a certain range.

From results as mentioned above, it can be seen that the deflection cone can effectively collect the trajectory of soybeans and reduce the dust diffusion. At the low low rate of $1 \mathrm{t} / \mathrm{h}$, the particle diffusion range without the deflection cone is the largest;

At a high material flow rate of $2.5 \mathrm{t} / \mathrm{h}$, the deflection cone has the same effect. Comparing the results of the same deflection cone position under different material flow rates, it can be seen that high material flow rate is also conducive to collecting particle flow and inhibiting dust diffusion. When the material flow rate is high, the collision constraint between particles is more obvious and plays a guiding role. Therefore, even if there is no the deflection cone, the degree of particle diffusion is also significantly weaker than that of low material flow rate. When the deflection cone is reduced to the position of $30 \mathrm{~mm}$, the blocking phenomenon occurs in the hopper, indicating that the annular channel at this position is too narrow to reach the material flow rate of $2.5 \mathrm{t} / \mathrm{h}$.
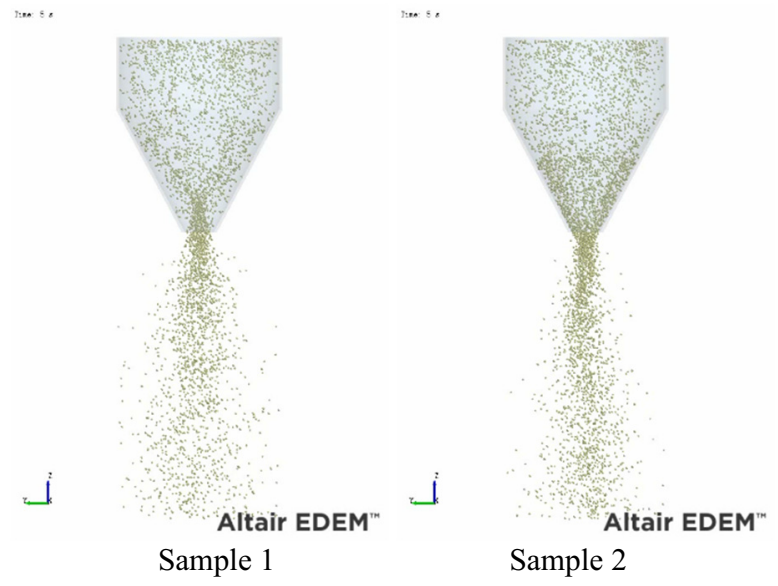

Sample 2

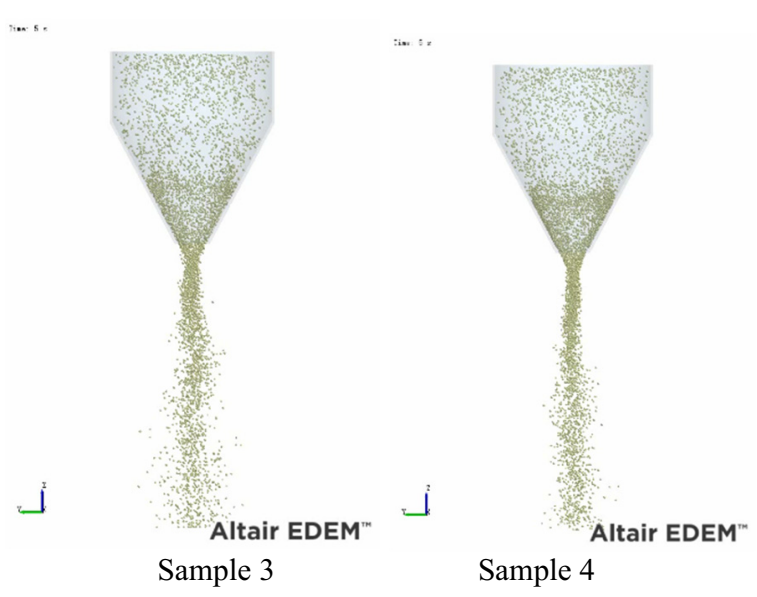

Fig.6. Particle behavior of different samples at the flow of $1.0 \mathrm{t} / \mathrm{h}$

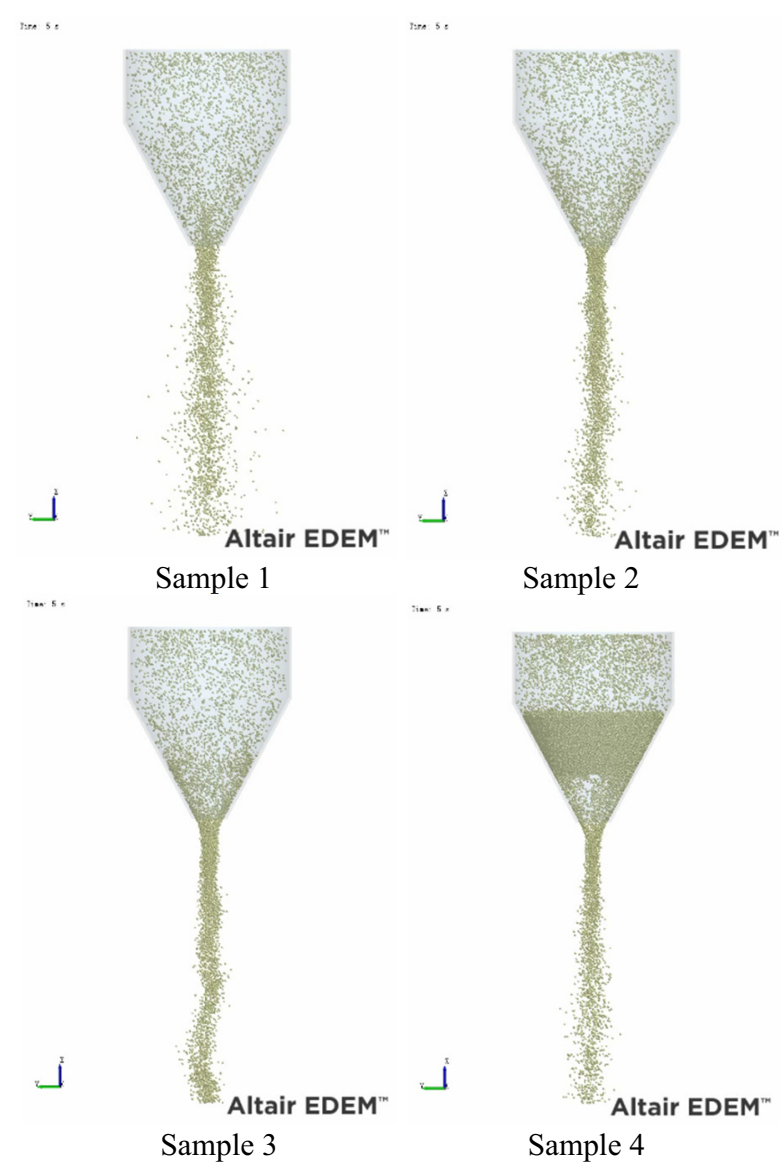

Fig.7. Particle behavior of different samples at the flow of $2.5 \mathrm{t} / \mathrm{h}$

Figure 8 demonstrates that after the deflection cone is added, the lower the position, the better the effect of the particle flow. This phenomenon shows that the annular channel formed by the deflection cone and the inner wall of the hopper has a guiding effect on the particle movement, and weakens the severe collision when the particle flow converges, thereby inhibiting the dust diffusion. 


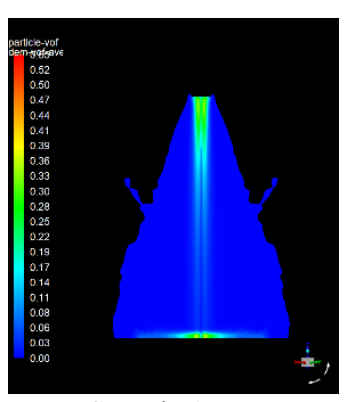

Sample 1

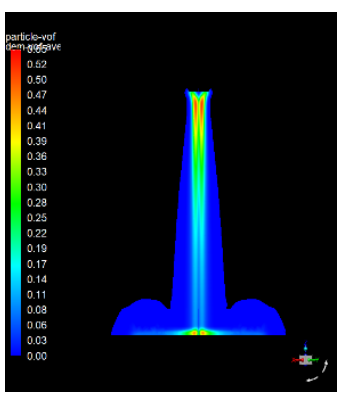

Sample 3

Fig. 8. the percentage of dust particle for different hoppers

\section{Summary}

Hoppers are important in the bulk cargo distribution. In this paper, different hoppers were proposed a the discrete element method. Results shows that structure of the hopper greatly affected the particle behavior which has an important effect on the performance of hoppers . After adding the deflection cone in the hopper, the trajectory of particle material can be effectively restrained and the dust diffusion can be reduced. The annular channel formed by the deflection cone and the inner wall of the hopper has a guiding effect on the particle movement. In future, more factors that affect performance of hoppers will be studies and provide instruction for hopper design.

\section{References}

1. Panpan Zhang, Simulation of Particle Behavior for Different Hoppers, Advances in Engineering Research, Vol.125(2017):228-231.

2. Wypych P., Cook D., Cooper P. Controlling dust emissions and explosion hazards in powder handling plants $[\mathrm{J}]$. Chemical Engineering and processing.2005, 44:323-326.

3. Liu Z.Q., Ma L.Y., Zhao X.Y. . Experimental Study the affection of the Dust Emission on Sand Stockpile by the Height of Windbreak Wall and Wind Speed. Applied Mechanics and Materials, 2014, 823:989-994.

4. Ai, Jun, Jian-Fei Chen, J. Michael Rotter, and Jin Y Ooi. Assessment of rolling resistance models in discrete element simulations. Powder Technology 206 (2011): 269-282.

5. Baran, Oleh, Alfred DeGennaro, Enrique Rame, and Allen Wilkinson. DEM Simulation of a Schulze Ring Shear Tester. Proceedings of the 6th International Conference on Micromechanics of Granular Media. 2009. 409-412.

6. Information on https://www.altair.com/edem/ 